\title{
Perbandingan Aktivitas Antioksidan Dari Tongkol Jagung (Zea mays L.) Segar dan Kering Dengan Metode Refluks
}

\author{
Ryan Vanly Saryana ${ }^{a^{*}}$, Edi Suryantoa, Meiske S. Sangia \\ aJurusan Kimia, FMIPA, Unsrat, Manado
}

\begin{tabular}{l}
\hline K A T A K U N C I \\
\hline Antioksidan \\
Tongkol jagung \\
Refluks \\
Ekstrak air
\end{tabular}

\begin{abstract}
A B S T R A K
Tujuan pada penelitian ini adalah menentukan potensi antioksidan ekstrak air dari tongkol jagung. Tongkol jagung yang sudah dikering anginkan digiling sedangkan yang segar hanya dicincincang hingga halus kemudian diekstraksi menggunakan metode refluks selama 0, 1, 2, 3 dan 4 jam menggunakan pelarut akuades. Analisis kandungan total fenolik, flavonoid dan tanin terkondensasi menggunakan spektrofotometer UV-Vis. Untuk penentuan penangkal radikal bebas menggunakan metode 1.1diphenyl-2.-picrylhydrazyl (DPPH). Hasil dari penelitian ini menunjukkan bahwa tongkol jagung kering memiliki kandungan total senyawa fenolik, flavonoid dan DPPH terbaik dengan pemanasan selama 4 jam. Akan tetapi total tanin terkondensasi terbaik terdapat pada tongkol jagung segar dengan pemanasan selama 4 jam.
\end{abstract}

\section{K E Y W O R D S}

Antioxidant

Corn cob

Reflux

Water extract
A B S T R A C T

The purpose of this study was to determine the antioxidant potential of water extract of corn cobs. Corn cobs wind dried milled while fresh only chopped until smooth then extracted using the reflux method for $0,1,2,3$ and 4 hours using distilled water solvent. Analysis of total phenolic content, flavonoids and condensed tannins using UV-Vis spectrophotometer. For the determination of free-radical scavengers using the method of 1.1-diphenyl-2-picrylhydrazyl (DPPH). The results of this study indicate that the dried corn cobs have the best content of total phenolic compounds, flavonoids and DPPH by heating for 4 hours. But, the total condensed tannins are best fresh on corn cob with heating for 4 hours.

\section{Pendahuluan}

Padatnya aktivitas masyrakat menyebabkan masyarakat mengkon-sumsi makanan cepat saji dan hidup dalam pola hidup yang tidak sehat. Pola makan yang tidak sehat dapat mengakibatkan radikal bebas di dalam tubuh dalam jangka panjang. Radikal bebas dapat disebabkan karena mengkonsumsi makanan yang tinggi kadar lemak, polusi udara, asap rokok dan paparan sinar ultraviolet.

Jagung (Zea mays L.) meru-pakan salah satu tanaman yang tumbuh di Indonesia dan jagung merupakan komoditi tanaman pangan kedua terpenting setelah padi sedangkan dalam pemanfaatannya hanya diambil biji jagungnya sebagai bahan pangan sedangkan tongkolnya hanya dibuang sebagai limbah tapi terkadang digunakan sebagai pakan ternak. Richana et al. (2004) mengatakan bahwa dari berat jagung bertongkol, sekitar 40-50\% adalah tongkol dan sisanya adalah bijinya, oleh karena itu dapat diperkirakan untuk produksi jagung 13 juta ton (jagung pipilan) akan menghasilkan limbah tongkol jagung sekitar 10.6 juta ton/tahun.

Penelitian tentang tongkol jagung telah dilakukan oleh beberapa orang yaitu oleh Lumempouw et al. (2012a) tentang potensi 
antioksidan dari ekstrak etanol tongkol jagung (Zea mays L.), Lumempouw et al. (2012b) tentang aktivitas anti UV-B ekstrak fenolik dari tongkol jagung (Zea mays L.), Saleh et al. (2012) tentang aktivitas antioksidan dari ekstrak tongkol jagung (Zea mays L.), Wungkana et al. (2013) tentang aktivitas antioksidan dan tabir surya fraksi fenolik dar limbah tongkol jagung (Zea mays L.). Pada penelitian Suryanto et al. (2013) tentang the evaluation of singlet oxygen quenching and sunscreen activity of corncob extract, sedangkan untuk menentukan aktivitas antioksidan dari ekstrak air tongkol jagung manis sweet corn serta membandingkannya dalam keadaan segar maupun kering belum pernah ada yang melakukannya.

Penelitian ini bertujuan membandingkan kandungan total fenolik, flavonoid dan tanin serta aktivitas antioksidan dari tongkol jagung segar dan kering dengan metode refluks.

\section{Metode}

\subsection{Material penelitian}

Sampel tongkol jagung diperoleh dari sisa jagung yang berasal dari kota Tomohon, jagung yang digunakan yaitu jagung hibrida sweet corn dalam keadaan segar dan dalam keadaan kering. Bahan kimia yang digunakan yaitu, metanol, etanol, reagen Folin-Ciocalteau, vanilin, asam klorida, asam tiobarbiturat (TBA) dan asam trikloroasetat (TCA) yang diperoleh dari Merck (Darmstat, Germany). 1,1difenil-2-pikrilhidrazil (DPPH) dan akuades. Semua bahan kimia yang digunakan adalah analytical grade.

Peralatan yang digunakan dalam penelitian ini adalah alat-alat gelas pyrex Iwaki, ayakan 60 mes, mikropipet, penggiling, seperangkat alat refluks, pengaduk magnet, spatula stainless stell, vorteks, mortar, neraca analitik ER-180 A, oven Mammert, spektrofotometer UV-Vis Thermo Scientific Genesys 20.

\subsection{Persiapan Sampel}

Tongkol jagung dikering-anginkan kemudian dibersihkan dan dipotong kecil-kecil untuk digiling sampai halus setelah itu diayak dengan ayakan berukuran 40 mesh sedangkan tongkol jagung segar dipotong kecil-kecil dengan ukuran $2 \mathrm{~mm}$ dan langsung dilakukan ekstraksi.

Sebanyak $100 \mathrm{~g}$ tongkol jagung yang kering maupun segar di ekstraksi dengan cara di refluks menggunakan akuades selama 1, 2, 3 dan 4 jam dengan suhu $100{ }^{\circ} \mathrm{C}$ selanjutnya di-saring. Metode refluks dilakukan dengan beberapa jam bertujuan untuk mengetahui proses pemanasan manakah yang memiliki kandungan senyawa fitokimia dan penangkal radikal bebas yang paling baik. Ekstrak tongkol jagung yang diperoleh disimpan pada suhu $5^{\circ} \mathrm{C}$ sebelum dilakukan analisis.

\subsection{Penentuan Fitokimia}

\subsubsection{Penentuan Kandungan Total Fenolik}

Kandungan total fenolik ekstrak tongkol jagung ditentukan dengan menggunakan metode FolinCiocalteau (Conde et al., 1997). Sebanyak 0,1 mL larutan ekstrak $1 \mathrm{mg} / \mathrm{mL}$ dimasukan ke dalam tabung reaksi dan ditambahkan $0,1 \mathrm{~mL}$ reagen Folin-Ciocalteau 50\%. Kemudian vorteks kurang lebih selama 3 menit dan ditambahkan $2 \mathrm{~mL}$ larutan $\mathrm{Na}_{2} \mathrm{CO}_{3} 2 \%$ lalu divorteks kembali. Selanjutnya campuran diinkubasi selama 30 menit pada suhu ruang. Absorbansi ekstrak dibaca pada spektrofotometer UV-Vis dengan panjang gelombang $750 \mathrm{~nm}$. Kandungan total fenolik dinyatakan sebagai $\mathrm{mg}$ ekivalen asam galat $\mathrm{mg} / \mathrm{mL}$ ekstrak.

\subsubsection{Penentuan Kandungan Total Flavonoid}

Kandungan total flavonoid ekstrak tongkol jagung ditentukan menurut metode Meda et al. (2005). Sebanyak $2 \mathrm{~mL}$ larutan ekstrak 0,5 mg/mL dimasukan dalam tabung reaksi lalu ditambah dengan $2 \mathrm{~mL} \mathrm{AlCl}_{3} 2 \%$ yang telah dilarutkan dalam etanol, kemudian divorteks. Absorbansi ekstrak dibaca pada spektrofotometer UV-Vis dengan panjang gelombang $415 \mathrm{~nm}$. Kandungan total flavonoid dinyatakan sebagai mg ekivalen kuesertin $\mathrm{mg} / \mathrm{mL}$ ekstrak.

\subsubsection{Penentuan Kandungan Total Tanin Terkondensasi}

Kandungan total tanin ekstrak tongkol jagung ditentukan menurut metode Julkenen-Tito (1985). Sebanyak $1 \mathrm{~mL}$ larutan ekstrak $0,5 \mathrm{mg} / \mathrm{mL}$ dimasukan dalam tabung reaksi yang dibungkus alumunium foil, lalu ditambahkan $2 \mathrm{~mL}$ vanilin $4 \%$ dalam metanol dan divorteks. Segera ditambahkan $1 \mathrm{~mL}$ asam klorida pekat dan divorteks lagi. Selanjutnya campuran diinkubasi selama 20 menit pada suhu ruang. Absorbansi ekstrak dibaca pada spektrofotometer UV-Vis dengan panjang gelombang $500 \mathrm{~nm}$. Kandungan total tanin terkondensasi dinyatakan sebagai $\mathrm{mg}$ ekivalen katekin $\mathrm{mg} / \mathrm{mL}$ ekstrak.

\subsubsection{Penentuan Penangkal Radikal Bebas DPPH}

Penentuan aktvitas penangkal radikal bebas DPPH menurut Burda dan Oleszek (2001). Sebanyak 0,5 mL ekstrak 0,5 mg/mL ditambahkan dengan $2 \mathrm{~mL}$ larutan 1,1-difenil-2-pikrilhidrazil (DPPH) $93 \mu \mathrm{M}$ dalam etanol dan divorteks selama 2 menit. Tingkat memudarnya warna larutan dari ungu menjadi kuning menunjukan efisiensi penangkap radikal bebas. Kemudian diinkubasi selama 30 menit pada suhu ruang. Absorbansi diukur pada panjang gelombang $517 \mathrm{~nm}$ dengan menggunakan spektrofotometer UV-Vis. Aktivitas penangkapan radikal bebas dihitung sebagai persentase berkurangnya warna DPPH dengan menggunakan persamaan:

Aktivitas penangkal radikal bebas (\%) =

$$
\left[1-\frac{\text { absorbansi sampel }}{\text { absorbansi kontrol }}\right] \times 100 \%
$$


3. Hasil dan Pembahasan

\subsection{Kandungan Total Fenolik, Flavonoid dan Tanin Terkondensasi}

Fenolik, flavonoid dan tanin terkondensasi deketahui merupakan senyawa-senyawa yang memiliki aktivitas sebagai antioksidan, sehingga perlu untuk diketahui total kandungan masingmasing senyawa tersebut baik dari ekstrak tongkol jagung manis kering (TJMK) maupun ekstrak tongkol jagung manis segar (TJMS).
Untuk menghitung kandungan total fenolik yang terdapat dalam tongkol jagung menggunakan persamaan regresi $\mathrm{mg}$ asam galat $\mathrm{mg} / \mathrm{mL}$ ekstrak, total flavonoid menggunakan persamaan regresi $\mathrm{mg}$ kuersetin $\mathrm{mg} / \mathrm{mL}$ ekstrak, sedangkan untuk menghitung total tanin menggunakan persamaan regresi $\mathrm{mg}$ katekin $\mathrm{mg} / \mathrm{mL}$ ekstrak. Digunakan persamaan regresi tersebut karena merupakan contoh dari masing-masing senyawa tersebut.

\subsubsection{Kandungan Total Fenolik}

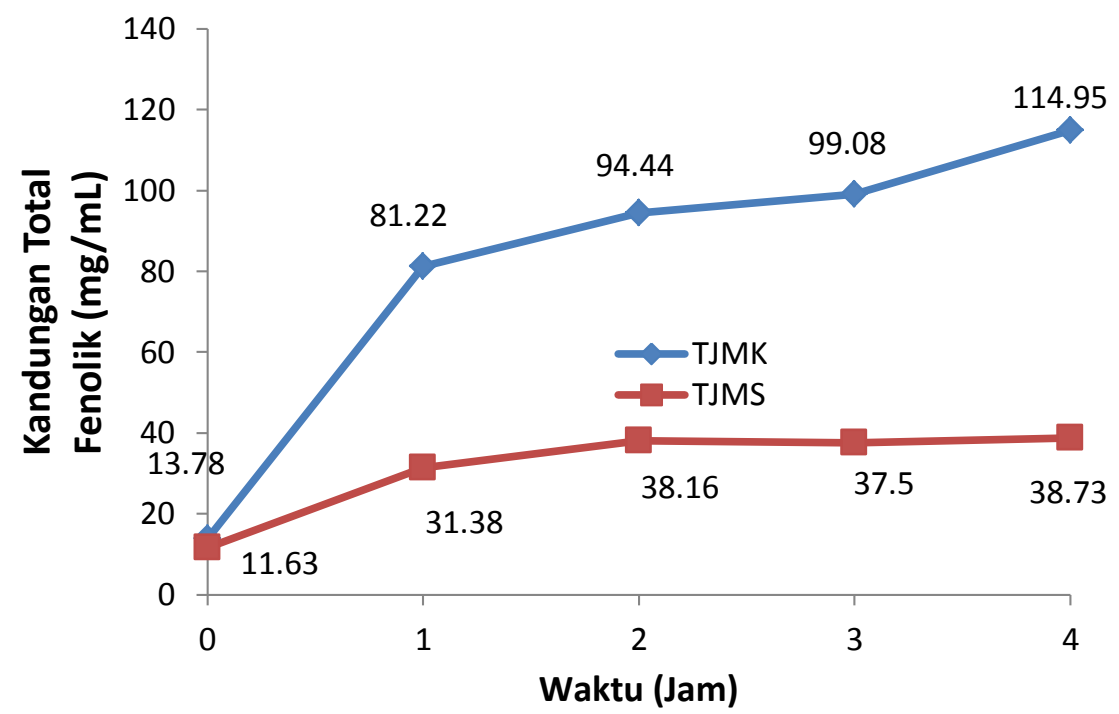

Gambar 1. Kandungan Total Senyawa Fenolik Tongkol Jagung Manis Kering (TJMK); Tongkol Jagung Manis Segar (TJMS)

Berdasarkan Gambar 1 bahwa ekstrak tongkol jagung manis kering yang diekstraksi dengan metode refluks selama 4 jam memiliki nilai fenolik yang paling tinggi dibandingkan dengan yang lainnya yaitu sebanyak $114.95 \mathrm{mg} / \mathrm{mL}$. Kandungan fenolik dengan metode Folin-Ciocalteau ditunjukkan dengan berubahnya warna larutan dari kuning menjadi biru, di karenakan reagen Folin-Ciocalteau yang mengandung senyawa asam fosfomolibdatfosfotungstat yang direduksi oleh sampel sehingga membentuk senyawa kompleks molibdenum tungstat berwarna biru. Warna biru yang terbentuk akan semakin pekat setara dengan konsentrasi ion fenolat yang terbentuk, artinya semakin besar konsentrasi senyawa fenolik maka semakin banyak ion yang mereduksi asam heteropoli sehingga warna biru yang dihasilkan semakin pekat. Semakin besar intensitas warna yang ditunjukkan maka akan semakin besar kandungan fenol yang terkandung (Julkenen-Titto, 1985).
Fenolik, flavonoid dan tanin terkondensasi deketahui merupakan senyawa-senyawa yang memiliki aktivitas sebagai antioksidan, sehingga

\subsubsection{Kandungan Total Flavonoid}

Gambar 2 menunjukkan bahwa nilai yang paling tinggi terdapat pada ekstrak tongkol jagung manis kering dengan waktu ekstraksi 4 jam dibandingkan dengan yang lainnya yaitu sebanyak $15.31 \mathrm{mg} / \mathrm{mL}$. Hal ini dapat disebabkan karena senyawa flavonoid dapat memebentuk kompleks dengan logam $\mathrm{Al}^{3+}$ pada gugus hidroksi (cincin A) dan keton (cincin $C$ ) yang bertetangga dan ortodihidroksi (cincin B) yang dapat menghasilkan warna kuning, sehingga dapat disimpulkan bahwa semakin kuat intensitas warna kuning maka kandungan flavonoid yang terkandung dalam ekstrak akan semakin tinggi (Meda et al., 2005). 


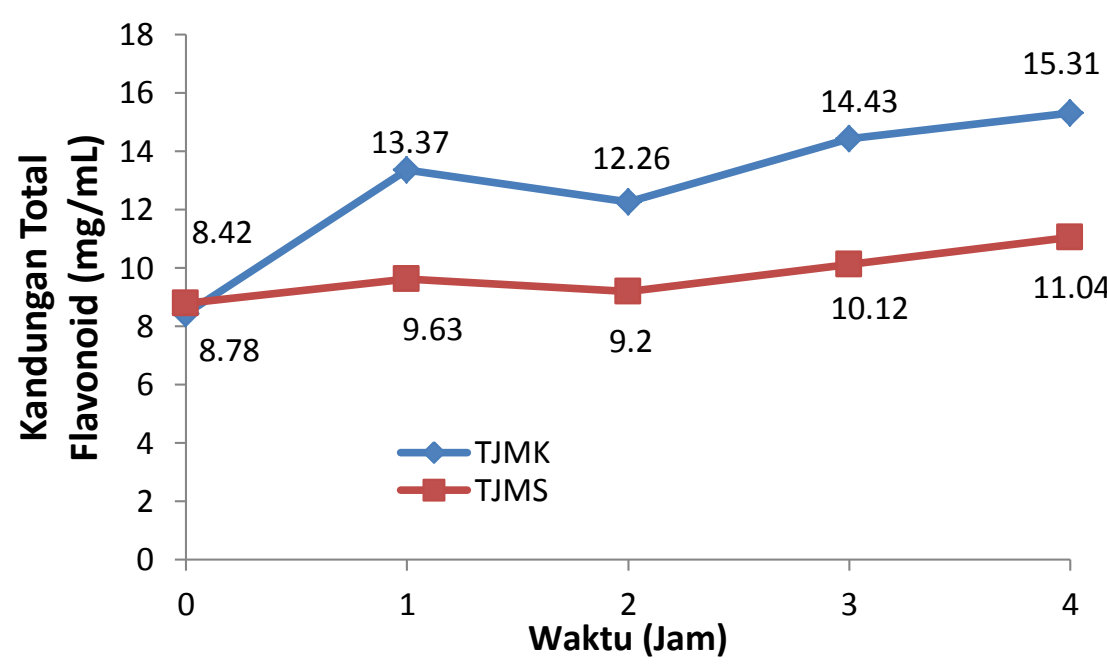

Gambar 2. Kandungan Total Senyawa Flavonoid Tongkol Jagung Manis Kering (TJMK); Tongkol Jagung Manis Segar (TJMS)

\subsubsection{Kandungan Total Tanin Terkondensasi}

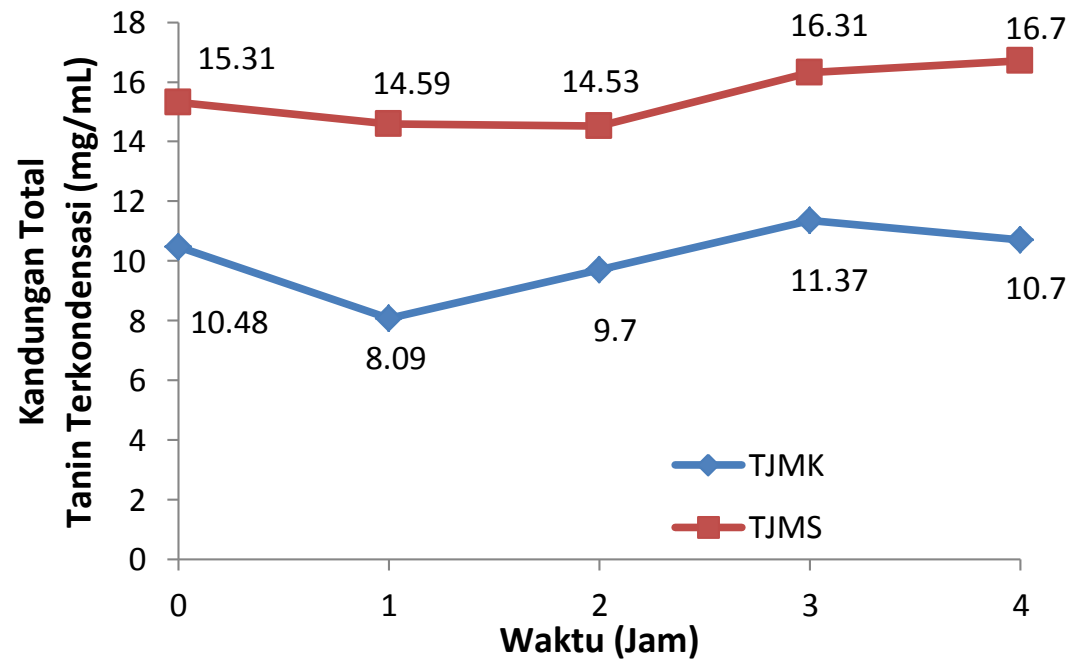

Gambar 2. Kandungan Total Senyawa Tanin Terkondensasi Tongkol Jagung Manis Kering (TJMK); Tongkol Jagung Manis Segar (TJMS)

Pada Gambar 3 menunjukkan bahwa kandungan tanin terkondensasi pada tongkol jagung segar memiliki nilai tertinggi pada waktu terlama selama proses ekstraksi yaitu 4 jam dibandingkan dengan nilai yang lainnya yaitu sebanyak 16.7 $\mathrm{mg} / \mathrm{mL}$. Dipilih tanin terkondensasi di karenakan tanin terkondensasi lebih tersebar luas jumlahnya daripada tanin yang terhidrolisis. Komponenkomponen uta-ma dari tanin terkondensasi adalah flavon-3-ol dimana senyawa tersebut termasuk kelompok flavonoid yang anggotanya tersebar luas dalam tumbuhan (Suryanto, 2012).

\subsubsection{Kandungan Total Tanin Terkondensasi}

Berdasarkan Gambar 4 bahwa persentase DPPH yang paling tinggi adalah ekstraksi dengan proses terlama yaitu 4 jam dengan nilai $69.78 \%$. Pada penelitian ini dapat dikatakan bahwa senyawa aktif yang terkandung di dalam ekstrak tongkol jagung memiliki kemampuan penangkal radikal bebas yang cukup baik. Kemampuan sebagai penangkal radikal bebas DPPH terbukti dari kemampuan ekstrak tongkol jagung yang melepaskan atom hidrogen kepada radikal difenilpikrihidrazil (ungu) menjadi senyawa nonradikal difenil-pikrilhidrazin (kuning).

Menurut Molyneux (2004), ketika larutan DPPH direaksikan dengan zat yang dapat menyumbangkan atom hidrogen, maka senyawa yang bereaksi sebagai penangkap radikal akan mereduksi DPPH yang dapat diamati dengan adanya perubahan warna DPPH dari warna ungu menjadi kuning. Hal ini disebabkan ketika elektron ganjil dari radikal DPPH telah berpasangan dengan hidrogen dari senyawa penangkap radikal bebas yang membentuk DPPH-H tereduksi. 


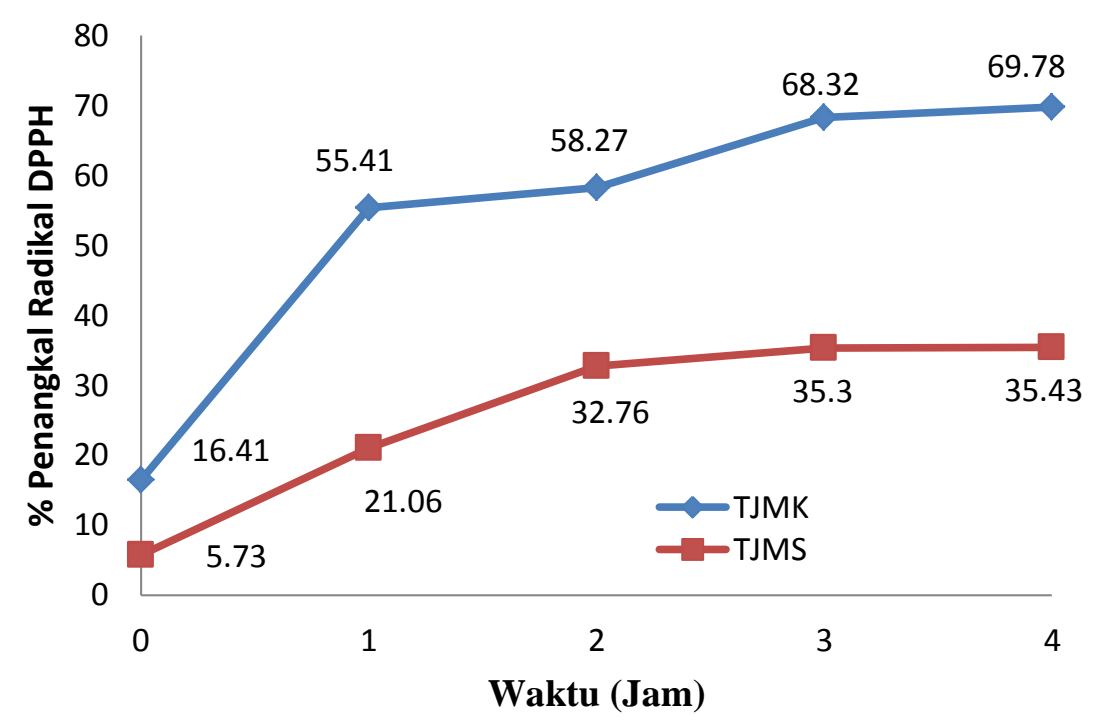

Gambar 4. Aktivitas Penangkal Radikal Bebas DPPH Tongkol Jagung Manis Kering (TJMK); Tongkol Jagung Manis Segar (TJMS)

\section{Kesimpulan}

Dari penelitian yang telah dilakukan dapat diketahui bahwa ekstrak air tongkol jagung kering memiliki kandungan senyawa fenolik, flavonoid dan aktivitas antioksidan yang dapat menangkal radikal bebas DPPH terbaik dibandingkan dengan tongkol jagung segar kecuali tanin.

\section{Daftar Pustaka}

Burda, S., dan W. Oleszek. 2001. Antioxidant and Antiradical Activities of Flavonoids. J. Agric. Food Chem. 49: 2774-2779.

Cholisoh, Z., dan W. Utami. 2008. Aktivitas Penangkal Radikal Ekstrak Etanol 70\% Biji Jengkol (Archidendron jiringa). J. Pharm. 9: 3340.

Conde, E.F., M.C.Cadahia, Garcia-Vallejo, B.F.D. Simon, dan J.R.G. Adrados. 1997. Low Molecular Weight Polyphenol in Cork of Quercus Suber. J. Agric. Food Chem. 45: 2695-2700.

Julkenen-Titto, R. 1985. Phenolic Constituents in the Leaves of Northern Willows: Methods for the Analysis of Certain Phenolic. J. Agric. Food Chem. 33: $213-217$.

Lumempouw, L. I., J. Paendong, L. I. Momuat, dan E. Suryanto. 2012a. Potensi Antioksidan Dari Ekstrak Etanol Tongkol Jagung (Zea mays L.). Chem. Prog. 5: 49-56.

Lumempouw, L. I., E. Suryanto, dan J. J. E. Paendong. 2012b. Aktivitas Anti UV-B Ekstrak
Fenolik Dari Tongkol Jagung (Zea mays L.). J. MIPA UNSRAT ONLINE. 1: 1-4.

Meda, A., C. E. Lamien, M. Romito, J. Miliogo, dan O. G. Nacoulina. 2005. Determination, of the Total Phenolic, Flavonoid and Proline Content in Burkina Fasan Money, As Activity. Food Chem. 91: 571-557.

Molyneux, P. 2004. The Use of the Stable Free Radical Diphenylpicrylhydrazyl (DPPH) for Estimating Antioxidant Activity. J. of Sci. Tech. 26: 211-219.

Richana, N., P. Lestina, dan T.T. Irawadi. 2004. Karakterisasi Lignoselulosa: Xylan dari Limbah Tanaman Pangan dan Pemanfaatannya untuk Pertumbuhan BakteriRXA III-5 Penghasil Xilanase. J. Penelitian Pertanian. 23: 171-176.

Saleh, L. P., E. Suryanto, dan A. Yudistira. 2012. Aktivitas Antioksidan Dari Ekstrak Tongkol Jagung (Zea mays L.). PHARMACON. 1: 20-24.

Suryanto, E. 2012. Fitokimia Antioksidan. CV. Putra Media Nusantara (PMN). Surabaya.

Suryanto, E., L. I. Momuat, A. Yudistira, dan F. Wehantouw. 2013. The Evaluation Of Singlet Oxygen Quenching And Sunscreen Activity Of Corncob Extract. Indonesian J. Pharm. 24: 269278.

Winarsi, H. 2007. Antioksidan Alami dan Radikal Bebas. Yogyakarta. Kanisius.

Wungkana, I., E. Suryanto, dan L. Momuat. 2013. Aktivitas Antioksidan Dan Tabiir Surya Fraksi Fenolik Dari Limbah Tongkol Jagung (Zea mays L.). PHARMACON. 2: 149-155. 